\title{
BMJ Open Risk of olfactory dysfunction of the workers in the automobile repair, printing, shoemaking and plating industries in Korea: a cross-sectional study
}

\author{
Soo-Jin Lee, ${ }^{1}$ Eun-Mi Kim, ${ }^{2}$ Seok-Hyun Cho, ${ }^{3}$ Jaechul Song, ${ }^{4}$ Tae-Won Jang, ${ }^{4}$ \\ Mi-Young Lee ${ }^{5}$
}

To cite: Lee S-J, Kim E-M, Cho S-H, et al. Risk of olfactory dysfunction of the workers in the automobile repair, printing, shoemaking and plating industries in Korea: a crosssectional study. BMJ Open 2018;8:e022678. doi:10.1136/ bmjopen-2018-022678

- Prepublication history for this paper is available online. To view these files, please visit the journal online (http://dx.doi org/10.1136/bmjopen-2018022678).

Received 2 March 2018 Revised 27 September 2018 Accepted 9 October 2018

\section{Check for updates}

(C) Author(s) (or their employer(s)) 2018. Re-use permitted under CC BY-NC. No commercial re-use. See rights and permissions. Published by BMJ.

${ }^{1}$ Department of Occupational and Environmental Medicine, Hanyang University Medical Center, Seoul, Korea

${ }^{2}$ Graduate School of Public Health, Hanyang University, Seoul, Korea

${ }^{3}$ Department of Otolaryngology, Hanyang University College of

Medicine, Seoul, Korea

${ }^{4}$ Department of Occupational and Environmental Medicine, Hanyang University College of Medicine, Seoul, Korea

${ }^{5}$ Occupational Health Research Bureau, Occupational Safety and Research Institute, Ulsan, Korea

Correspondence to

Dr Tae-Won Jang;

om1024@hanmail.net

\section{ABSTRACT}

Objectives The present study was performed to investigate the prevalence of olfactory dysfunction in workers exposed to hazardous substances in a variety of occupations in Korea.

Methods We designed a cross-sectional study. The exposed group ( $n=296$ ) consisted of Korean workers in the automobile repair, printing, shoemaking and plating industries and was compared with office workers (non-exposed group, $n=99$ ). A self-report questionnaire was administered to the subjects for demographic characteristics. In addition, olfactory function was evaluated using the Korean version of Sniffin's Stick (KVSS) I and II test, which has been reported to be valid and reliable in Korean subjects. KVSS I score $\geq 7$ or KVSS II score $\geq 30$ was classified as normal, KVSS I score $<7$ or KVSS II score $<30$ was classified as oflactory dysfunction. The statistical analyses were performed with olfactory dysfunction as a dependent variable to calculate prevalence ratio (PR) of the exposed group.

Results The prevalence of olfactory dysfunction was $21.2 \%$ in office, $45.1 \%$ in automobile repair, $69.7 \%$ in printing and $88.9 \%$ in shoemaking and plating workers. The adjusted PR was highest in plating $(3.589,95 \% \mathrm{Cl}$ 1.957 to 6.583$)$, followed by shoemaking $(3.136,95 \% \mathrm{Cl}$ 1.763 to 5.579$)$, printing $(2.669,95 \% \mathrm{Cl} 1.610$ to 4.424$)$ and automobile repair $(1.914,95 \% \mathrm{Cl} 1.105$ to 3.317$)$ workers.

Conclusions In comparison with office workers, the prevalence of olfactory dysfunction and the PR of olfactory dysfunction were very high in the four occupational groups. This finding could be an important basis for establishing the olfactory dysfunction prevention policy for workers who are exposed to hazardous substances or work in high-risk occupations.

\section{INTRODUCTION}

The human olfactory system modulates behaviour and interpersonal relationships and has been shown to have an important influence on nutritional status, eating satisfaction and quality of life. ${ }^{1-3}$ In addition to visual, auditory and vestibular function, the olfactory system also plays an important role
Strengths and limitations of this study

- The study investigated the prevalence of olfactory dysfunction in various occupational groups.

- Olfactory function testing with high validity and reliability was performed using the Korean version of Sniffin's Stick (KVSS); confounding factors associated with olfactory dysfunction were controlled.

- Different tests were performed on subjects in the two group: KVSS I in non-exposed group and KVSS I| in the exposed group.

in detecting changes in the environment, such as fire and gas leakage and olfactory dysfunction can, therefore, impact on safety. ${ }^{45}$

A variety of factors are known to be related to olfactory function. Olfactory dysfunction has been shown to decrease with age,${ }^{6-8}$ with the decline in cognitive function (including olfactory function) progressing more rapidly in men than women. ${ }^{9}$ High body mass index $(\mathrm{BMI}){ }^{10}$ cigarette smoking, ${ }^{11}$ race,${ }^{12}$ socioeconomic status ${ }^{12} 13$ and a history of head trauma $^{14}$ have been associated with olfactory dysfunction. Occupational and environmental factors, such as exposure to certain metals (eg, lead, ${ }^{15}$ cadmium $^{16}$ and manganese ${ }^{17}$ ), chemicals (eg, acetone, ${ }^{18}$ hydrogen sulfide, ${ }^{19}$ acrylate and methacrylate ${ }^{20}$ ) and pesticides (eg, chlorpyrifos ${ }^{21}$ and neonicotinoid $^{22}$ ), can also impact on olfactory function.

Workers in certain industries are commonly exposed to multiple hazardous substances during the course of their work. While there have been several studies of the relationship between exposure to hazardous substances, such as metals and solvents and olfactory dysfunction, few have investigated olfactory dysfunction in specific occupational groups. ${ }^{23}$ In addition, many previous studies have had key limitations in their design, such as inadequate evaluation of exposure, small 
subject numbers, lack of quantitative evaluation for olfactory function and inadequate control for confounding factors. ${ }^{23}$ We designed the cross-sectional study to investigate the prevalence of olfactory dysfunction in workers involved in various occupations and to evaluate the relationship between occupation and olfactory dysfunction.

\section{METHODS}

\section{Subjects}

Workers in automobile repair, printing, shoemaking and plating industries are known to be exposed to hazardous substances related with olfactory dysfunction. These workers were compared with non-exposed office workers.

An appropriate sample size was calculated with the Power and Sample Size Program V.3.1.2 and was calculated to be 250 in the exposed group and 82.5 in the non-exposed group, with a ratio for exposed and non-exposed group of 3:1. The initial number of subjects was 419. Subjects were excluded if there was sinusitis or sinus tumours associated with olfactory dysfunction $(n=6)$ or if the olfactory function test was not adequately performed $(n=26)$. The final number of subjects was $n=99$ in the non-exposed group and $n=296$ in the exposed group. The exposed group consisted of 82 automobile repair workers $(27.7 \%), 142$ printing workers $(48.0 \%)$, 45 shoemaking workers $(15.2 \%)$ and 27 plating workers $(9.1 \%)$. Ethics was approved by the Institutional Review Board of Hanyang University. Informed consent was obtained from all study subjects.

\section{Subjects and public involvement}

The subjects were not involved the design, recruitment and conduct of the present study. The recruitment was performed to all workers in each industry and those who agreed to participate in the present study were included. The subjects were informed of the objective of the present study before questionnaire survey and of the results of olfactory function test right after the test.

\section{Data collection}

A self-report questionnaire was designed to capture demographic characteristics including age, sex, height, weight, alcohol drinking, smoking and working period. The researchers checked the questionnaires and asked the subjects to fill any missing data fields if found.

The Korean version of Sniffin's Stick (KVSS) test has been shown to be valid and reliable for Korean subjects in comparison with the cross-cultural smell identification test(CC-SIT) ${ }^{24}{ }^{25}$ KVSS I is a screening test that consists of eight pens for odour identification. The subject smells each pen and choose one out of four answers. The number of correct answers among the eight pens is considered to be the KVSS I score, with a KVSS I score $\geq 7$ classified as normal, 5-6 indicating hyposmia and $\leq 4$ indicating anosmia. KVSS II is an extended version of the test that includes an olfactory threshold test, odour discrimination test and odour identification test. The olfactory threshold test consists of 16 olfactory test pens with diluted butanol (n-butanol). The test starts from the pen with the lowest concentration and gradually increases the concentration of the pen to decide the threshold. The odour discrimination test consists of three pairs of 16 olfactory test pens, which include two of the same odour pens and one different odour pen. The subject is asked to smell three pens and choose a different odour pen. The odour identification test consists of 16 olfactory test pens containing odours familiar to the Korean population. The subject is asked to smell each pen and choose the right answer among four items. The score obtained after performing the three tests is referred to as the Threshold, Discrimination and Identification (TDI) score and is classified as follows: normal (TDI score $\geq 30$ ), hyposmia (TDI score of 16-29) and anosmia (TDI score $\leq 15$ ).

The exposed group was recruited in 2016 and tested using the extended olfactory function test (KVSS II). The non-exposed group were recruited in 2017 , however due to time constraints were tested using the KVSS I. In addition, non-exposed group was considered as low-risk group for olfactory dysfunction, so we thought screening test (KVSS I) was appropriate for them. Subjects were classified as having normal or olfactory function according to the scores for KVSS I and II. In addition, the exposed group was classified further according to the score of odour identification test in KVSS II $(\geq 13=$ normal, $\leq 12=$ odour identification impairment). The research was performed from May 2016 to July 2017.

\section{Statistical analysis}

Age was categorised as 20-29, 30-39, 40-49 and $\geq 50$ in years. BMI was categorised as <23.0, 23.0-24.9 and $\geq 25.0 \mathrm{~kg} / \mathrm{m}^{2}$. Alcohol drinking was categorised as either 'none or social' or 'moderate or heavy'. Moderate or heavy alcohol drinking was defined as drinking alcohol more than once a week. Working period was categorised as $0-9,10-19,20-29$ and $\geq 30$ years. Statistical analyses were performed with SAS Windows V.9.4. The demographic characteristics between the exposed and non-exposed groups were compared using a $\chi^{2}$ test. The prevalence ratio (PR) of the exposed group was estimated with $95 \%$ CI using PROC GENMOD statement of SAS Windows V.9.4. Dependent variables were olfactory dysfunction and odour identification impairment and independent variables included age, sex, BMI, alcohol drinking and cigarette smoking. Age and BMI were treated as continuous variables and other variables were treated as categorical variables. The statistical significance level was set at $\mathrm{p}<0.05$.

\section{RESULTS}

The demographic characteristics of all study subjects are shown in table 1 . The mean age of subjects in the exposed group (45.8 \pm 10.5 years) was significantly higher than that of the non-exposed group $(38.2 \pm 8.4$ years, $\mathrm{p}<0.05)$. The proportion of obese subjects $\left(B M I \geq 25 \mathrm{~kg} / \mathrm{m}^{2}\right)$ was 
Table 1 Demographic characteristics of study subjects.

\begin{tabular}{|c|c|c|c|}
\hline & $\begin{array}{l}\text { Non-exposed } \\
(\mathrm{n}=99)\end{array}$ & $\begin{array}{l}\text { Exposed } \\
(n=296)\end{array}$ & $P$ values \\
\hline Age (years) & $38.2 \pm 8.4$ & $45.8 \pm 10.5$ & $<0.0001$ \\
\hline $20-29$ & $15(15.2)$ & $24(8.1)$ & \\
\hline $30-39$ & $48(48.5)$ & $61(20.6)$ & \\
\hline $40-49$ & $23(23.2)$ & $92(31.1)$ & \\
\hline$\geq 50$ & $13(13.1)$ & $119(40.2)$ & \\
\hline Sex & & & 0.0570 \\
\hline Male & $89(89.9)$ & $242(81.8)$ & \\
\hline Female & $10(10.1)$ & $54(18.2)$ & \\
\hline $\mathrm{BMI}\left(\mathrm{kg} / \mathrm{m}^{2}\right)$ & & & 0.0266 \\
\hline$<23$ & 34 (34.3) & $134(45.3)$ & \\
\hline $23-25$ & 27 (27.3) & $89(30.1)$ & \\
\hline$\geq 25$ & $38(38.4)$ & $73(24.6)$ & \\
\hline Alcohol drinking & & & 0.3324 \\
\hline Non-drinker or social drinker & $25(25.3)$ & 61 (20.6) & \\
\hline Moderate or heavy drinker ${ }^{*}$ & $74(74.7)$ & $235(79.4)$ & \\
\hline Smoking & & & 0.1960 \\
\hline Non-smoker or ex-smoker & $43(43.4)$ & $107(36.1)$ & \\
\hline Current smoker & $56(56.6)$ & $189(74.9)$ & \\
\hline Working period (years) & & & $<0.0001$ \\
\hline $0-9$ & $58(58.6)$ & $100(33.8)$ & \\
\hline $10-19$ & $24(24.2)$ & $74(25.0)$ & \\
\hline $20-29$ & $16(16.2)$ & $63(21.3)$ & \\
\hline$\geq 30$ & $1(1.0)$ & 59 (19.9) & \\
\hline Job & & & $<0.0001$ \\
\hline Office work & $99(100.0)$ & $0(0.0)$ & \\
\hline Automobile repair & $0(0.0)$ & $82(27.7)$ & \\
\hline Printing & $0(0.0)$ & $142(48.0)$ & \\
\hline Shoemaking & $0(0.0)$ & 45 (15.2) & \\
\hline Plating & $0(0.0)$ & $27(9.1)$ & \\
\hline
\end{tabular}

Data are shown as mean \pm SD or number (\%).

*Drinking alcohol more than once a week.

BMI, body mass index.

significantly higher in the non-exposed group $(38.4 \%)$ than in the exposed group $(24.6 \%, \mathrm{p}<0.05)$. No significant differences were seen between the two groups with respect to alcohol drinking and smoking. More than half of the non-exposed group had $<10$ years working period $(58.6 \%)$ compared with a third of the exposed group $(33.8 \%)$.

Table 2 shows the prevalence of olfactory dysfunction and odour identification impairment. In the non-exposed group, the prevalence of olfactory dysfunction was $21.2 \%$, which was lower than any of the occupations in the exposed groups (shoemaking and plating: 88.9\% each; printing: $69.7 \%$ and automobile repair: $45.1 \%$ ). The prevalence of odour identification impairment was highest in the plating group (96.3\%), followed by shoemaking $(86.7 \%)$, printing $(82.3 \%)$ and automobile repair $(54.9 \%)$.

Table 3 shows the association between occupation and olfactory dysfunction and odour identification impairment. The PRs of all occupations in the exposed group were significantly greater than 1.0. For olfactory dysfunction, adjusted PR was highest in plating $(3.589,95 \%$ CI 1.957 to 6.583 ), followed by shoemaking $(3.136,95 \% \mathrm{CI}$ 1.763 to 5.579$)$, printing $(2.669,95 \%$ CI 1.610 to 4.424$)$ and automobile repair $(1.914,95 \%$ CI 1.105 to 3.317$)$ workers. For odour identification impairment, adjusted PR was highest in plating (3.657, 95\% CI 2.015 to 6.635), followed by printing (2.979, 95\% CI 1.811 to 4.898$)$, shoemaking (2.892, 95\% CI 1.630 to 5.129) and automobile repair $(2.386,95 \%$ CI 1.402 to 4.059$)$. 
Table 2 Prevalence for olfactory dysfunction and olfactory identification impairment.

\begin{tabular}{lcc}
\hline Job & $\begin{array}{l}\text { Olfactory } \\
\text { dysfunction* }\end{array}$ & $\begin{array}{l}\text { Odour } \\
\text { identification } \\
\text { impairment† }\end{array}$ \\
\hline Office work & $21(21.2)$ & $21(21.2)$ \\
\hline Automobile repair & $37(45.1)$ & $45(54.9)$ \\
Printing & $99(69.7)$ & $117(82.3)$ \\
Shoemaking & $40(88.9)$ & $39(86.7)$ \\
\hline Plating & $24(88.9)$ & $26(96.3)$ \\
\hline
\end{tabular}

Data are shown as number (\%).

*Evaluated with KVSS I (office work) or TDI score of KVSS II (automobile repair, printing, shoemaking and plating). †Evaluated with KVSS I (office work) or odour identification test in KVSS II (automobile repair, printing, shoemaking and plating). KVSS, Korean version of Sniffin's Stick; TDI, Threshold, Discrimination and Identification.

\section{DISCUSSION}

The present study was designed to investigate the prevalence of olfactory dysfunction in variety of occupations known to be exposed to hazardous substances and the relationship between occupation and olfactory dysfunction. In comparison with office workers, the prevalence of olfactory dysfunction was higher in the exposed occupational groups $(45.1 \%$ in automobile repair group, $69.7 \%$ in printing and $88.9 \%$ in shoemaking and plating versus $21.2 \%$ in office workers). All occupations in the exposed group exhibited elevated risk of olfactory dysfunction and odour identification impairment, with the risk being highest in plating, followed by shoemaking, printing and automobile repair.

The reported prevalence of olfactory dysfunction in the general population has been shown to differ across a number of published studies and may vary depending on the target population and the method of testing.
Schubert et $a l^{13}$ performed odour identification test in 2838 participants aged 21-84 years and reported that the prevalence of olfactory impairment was $3.8 \%$. In Korea, the prevalence of subjective olfactory dysfunction was $5.4 \%$, which was derived from a self-reported questionnaire on 24990 participants aged 20-98 in the Korea National Health and Nutrition Examination Survey from 2008 to 2012. ${ }^{26}$ Among 2491 participants of old age (53-97 years), the prevalence of impaired olfaction using the San Diego Odor Identification Test (SDOIT) was $24.5 \%{ }^{8}$ Vennemann et $a l^{11}$ measured the olfactory function using Sniffin's Sticks test in 1312 participants (mean age 52.1 years) and reported that the prevalence of olfactory dysfunction was $18.0 \%$. Brämerson et $a l^{27}$ performed the Scandinavian Odor Identification Test in 1387 participants of all age groups (from 20 to $>80$ years) and reported that the prevalence of olfactory dysfunction was $19.1 \%$ ( $13.3 \%$ of hyposmia and $5.8 \%$ of anosmia).

There are many studies about the prevalence of olfactory dysfunction in the general population, but few studies have investigated the prevalence of olfactory dysfunction in specific occupational groups. Watanabe and Fukuchi ${ }^{28}$ conducted the olfactory function test in 33 workers in a chromate-producing factory, reporting that $54.5 \%$ exhibited olfactory dysfunction. Rose $e t a l^{29}$ examined 55 workers exposed to cadmium fumes in a brazing operation and reported that $56.4 \%$ exhibited olfactory dysfunction (43.6\% mild hyposmia and $12.7 \%$ moderate or severe hyposmia). Mascagni $e t a l^{30}$ investigated olfactory function in 33 workers employed in cadmium fusion, sintering and alloy lamination, reporting that $30.3 \%$ of study subjects exhibited olfactory dysfunction. Rydzewski et $a l^{11}$ evaluated the olfactory function test in 73 workers in a cadmium-nickel battery plant and found that $45.2 \%$ had olfactory dysfunction (26.0\% hyposmia, $17.8 \%$ parosmia and $1.4 \%$ anosmia). Antunes $e t a l^{2}$ performed the University of Pennsylvania Smell Identification Test

Table 3 The association between job and olfactory dysfunction and olfactory identification impairment.

\begin{tabular}{lll}
\hline Job & Crude prevalence ratio (PR) & Adjusted PR $^{*}$ \\
\hline Olfactory dysfunction & & \\
$\quad$ Office work & 1.000 & 1.000 \\
\hline Automobile repair & $2.127(1.245-3.634)$ & $1.914(1.105-3.317)$ \\
\hline Printing & $3.287(2.052-5.263)$ & $2.669(1.610-4.424)$ \\
$\quad$ Shoemaking & $4.191(2.471-7.106)$ & $3.136(1.763-5.579)$ \\
\hline Plating & $4.191(2.333-7.527)$ & $3.589(1.957-6.583)$ \\
\hline Odour identification impairment & & \\
\hline Office work & 1.000 & 1.000 \\
\hline Automobile repair & $2.587(1.541-4.343)$ & $2.386(1.402-4.059)$ \\
Printing & $3.884(2.441-6.181)$ & $2.979(1.811-4.898)$ \\
\hline Shoemaking & $4.086(2.404-6.945)$ & $2.892(1.630-5.129)$ \\
\hline Plating & $4.540(2.554-8.068)$ & $3.657(2.015-6.635)$
\end{tabular}

Data are shown as PR $(95 \% \mathrm{Cl})$.

${ }^{*}$ Adjusted for age, sex, body mass index, medical history, alcohol drinking and smoking. 
(UPSIT) in 43 welders and matched control subjects, demonstrating that $88.0 \%$ of welders had a UPSIT score lower than their matched controls. According to the above researches, the prevalence of various occupations was reported to be $45.2 \%-88.0 \%$, which is much higher than that of the general population from previous researches $(3.8 \%-24.5 \%)$. In the present study, the prevalence of olfactory dysfunction in the exposed groups was much higher than that of the non-exposed group, which is consistent with the previous researches.

According to a review of olfactory toxicity and the longterm effects of occupational exposure, various metals and chemicals have been associated with olfactory dysfunction in exposed workers. Metals known to have an effect on the olfactory system include arsenic, cadmium, chromium, copper, mercury, nickel and zinc; chemicals include acetone, acrylate, methacrylate, benzene, toluene, trichloroethylene, xylene and solvent mixtures. ${ }^{23}$ However, few studies have assessed the magnitude of the risk associated with these hazardous substances or occupational groups. Schwartz et al investigated the risk of acrylate and methacrylate vapours on olfactory dysfunction, and reported the OR for acrylate and methacrylate exposure to be 3.1 (95\% CI 1.2 to 7.7) ${ }^{20}$ They also reported a dose-response relationship between olfactory dysfunction and cumulative lifetime exposure to acrylates. Most studies have compared the subjective symptoms for olfactory dysfunction or the results of olfactory function testing between exposed and control groups, but did not investigate the relative risk or OR of hazardous substances or occupations on olfactory dysfunction.

In the present study, the adjusted PRs of all occupations in the exposed group were very high. A variety of potentially hazardous substances are used in the process of plating, that is, acids (sulfuric, hydrochloric and nitric), metals (zinc, nickel, chrome and copper) and solvents (trichlorethylene, ethylbenzene, xylene and toluene). ${ }^{33} 34$ Hazardous substances commonly used in the process of shoemaking include solvents, such as benzene, xylene, ethyl benzene, toluene and n-hexane. ${ }^{35}$ Solvents are also the main source of exposure in the printing process, with n-hexane, acetone, isopropyl alcohol, toluene and xylene being the most common substances used. ${ }^{36}$ In the process of automobile repair, workers may be exposed to solvents (toluene, xylene, acetone, isopropyl alcohol, methyl ethyl ketone and styrene) and metals (zinc, chrome, manganese and cadmium). ${ }^{37} 38$ Most workers are exposed to a variety of chemical substances rather than a single substance. In addition, occupational olfactory dysfunction may also likely occur due to an exposure of various chemical substances rather than a single substance. Therefore, future study about occupational olfactory dysfunction should focus on occupations which may have risk for olfactory dysfunction.

The present study has some limitations. First, the subjects of the present study were not representative for all workers. So, it is difficult to generalise the results of the present study. Second, the present study was cross-sectional study, so the finding of the present study means the association, not causal relationship. Third, the KVSS I was used to assess olfactory function in the office worker group, while the KVSS II was performed in the occupational groups. KVSS I is a screening test that includes odour identification only, whereas KVSS II is an extended test that includes an olfactory threshold test, odour discrimination test and odour identification test. As the dependent variable of olfactory dysfunction was derived from different tests in the office workers and occupational groups, statistical analysis may be inappropriate. However, the correlation between the KVSS I, II and CC-SIT scores has been reported to be extremely high. ${ }^{25}$ We, therefore, consider that given the high correlation between KVSS I and II scores, the use of different tests was not a significant issue.

In conclusion, the prevalence of olfactory dysfunction was seen to be $21.2 \%$ in office workers, while notably higher rates were seen in the exposed group: $45.1 \%$ in automobile repair, $69.7 \%$ in printing and $88.9 \%$ in shoemaking and plating. In addition, the PR of olfactory dysfunction in the occupations of the exposed group was very high compared with office workers. To prevent the olfactory dysfunction in these occupations, it is recommended to inform workers about the health hazards of chemicals and metals, encourage them to wear protective equipment and provide periodic health examinations including olfactory function test. The findings of the present study could be an important basis for establishing an olfactory dysfunction prevention policy for workers who are exposed to hazardous substances or work in highrisk occupations.

Contributors S-JL Lee drafted the manuscript. E-MK Kim contributed to the questionnaire survey. S-HC Cho performed the olfactory function testing. JS contributed to the study design and interpretation of the manuscript. T-WJ contributed to the study design, statistical analysis, and revision of the manuscript. $\mathrm{M}-\mathrm{YL}$ contributed to the statistical analysis and revision of manuscript.

Funding This research was supported by the Occupational Safety and Health Research Institute of Korea.

Competing interests None declared.

Patient consent Obtained.

Ethics approval Institutional Review Board of Hanyang University.

Provenance and peer review Not commissioned; externally peer reviewed. Data sharing statement No additional data available.

Open access This is an open access article distributed in accordance with the Creative Commons Attribution Non Commercial (CC BY-NC 4.0) license, which permits others to distribute, remix, adapt, build upon this work non-commercially, and license their derivative works on different terms, provided the original work is properly cited, appropriate credit is given, any changes made indicated, and the use is non-commercial. See: http://creativecommons.org/licenses/by-nc/4.0/.

\section{REFERENCES}

1. Santos DV, Reiter ER, DiNardo LJ, et al. Hazardous events associated with impaired olfactory function. Arch Otolaryngol Head Neck Surg 2004;130:317-9.

2. Hummel T, Nordin S. Olfactory disorders and their consequences for quality of life. Acta Otolaryngol 2005;125:116-21.

3. Sarafoleanu C, Mella C, Georgescu M, et al. The importance of the olfactory sense in the human behavior and evolution. $J$ Med Life 2009;2:196-8. 
4. Blomqvist EH, Brämerson A, Stjärne P, et al. Consequences of olfactory loss and adopted coping strategies. Rhinology 2004;42:189-94.

5. Pence TS, Reiter ER, DiNardo LJ, et al. Risk factors for hazardous events in olfactory-impaired patients. JAMA Otolaryngol Head Neck Surg 2014;140:951-5.

6. Hoffman HJ, Ishii EK, MacTurk RH. Age-related changes in the prevalence of smell/taste problems among the United States adult population. Results of the 1994 disability supplement to the National Health Interview Survey (NHIS). Ann N Y Acad Sci 1998;855:716-22.

7. Larsson M, Finkel D, Pedersen NL. Odor identification: influences of age, gender, cognition, and personality. J Gerontol B Psychol Sci Soc Sci 2000;55:P304-10.

8. Murphy C, Schubert CR, Cruickshanks KJ, et al. Prevalence of olfactory impairment in older adults. JAMA 2002;288:2307-12.

9. Lipnicki DM, Sachdev PS, Crawford J, et al. Risk factors for late-life cognitive decline and variation with age and sex in the Sydney Memory and Ageing Study. PLoS One 2013;8:e65841.

10. Patel ZM, DelGaudio JM, Wise SK. Higher body mass index Is associated with subjective olfactory dysfunction. Behav Neurol 2015;2015:1-4.

11. Vennemann MM, Hummel T, Berger K. The association between smoking and smell and taste impairment in the general population. J Neurol 2008;255:1121-6.

12. Noel J, Habib AR, Thamboo A, et al. Variables associated with olfactory disorders in adults: A U. S. population-based analysis. World J Otorhinolaryngol Head Neck Surg 2017;3:9-16.

13. Schubert CR, Cruickshanks KJ, Fischer ME, et al. Olfactory impairment in an adult population: the Beaver Dam Offspring Study. Chem Senses 2012;37:325-34.

14. Doty RL, Yousem DM, Pham LT, et al. Olfactory dysfunction in patients with head trauma. Arch Neurol 1997;54:1131-40.

15. Grashow R, Sparrow D, Hu H, et al. Cumulative lead exposure is associated with reduced olfactory recognition performance in elderly men: the normative aging study. Neurotoxicology 2015;49:158-64.

16. Sulkowski WJ, Rydzewski B, Miarzynska M. Smell impairment in workers occupationally exposed to cadmium. Acta Otolaryngol 2000;120:316-8.

17. Guarneros M, Ortiz-Romo N, Alcaraz-Zubeldia M, et al. Nonoccupational environmental exposure to manganese is linked to deficits in peripheral and central olfactory function. Chem Senses 2013;38:783-91.

18. Dalton P, Wysocki CJ, Brody MJ, et al. Perceived odor, irritation, and health symptoms following short-term exposure to acetone. $\mathrm{Am} \mathrm{J}$ Ind Med 1997;31:558-69.

19. Hirsch AR, Zavala G. Long-term effects on the olfactory system of exposure to hydrogen sulphide. Occup Environ Med 1999;56:284-7.

20. Schwartz BS, Doty RL, Monroe C, et al. Olfactory function in chemical workers exposed to acrylate and methacrylate vapors. Am J Public Health 1989;79:613-8.
21. Dick RB, Steenland K, Krieg EF, et al. Evaluation of acute sensory-motor effects and test sensitivity using termiticide workers exposed to chlorpyrifos. Neurotoxicol Teratol 2001;23:381-93.

22. Li H, Wu F, Zhao L, et al. Neonicotinoid insecticide interact with honeybee odorant-binding protein: Implication for olfactory dysfunction. Int J Biol Macromol 2015;81:624-30.

23. Gobba F. Olfactory toxicity: long-term effects of occupational exposures. Int Arch Occup Environ Health 2006;79:322-31.

24. Hong SC, Yoo YS, Kim ES, et al. Development of KVSS Test (Korean Version of Sniffin' Sticks Test). Korean J Otolaryngol 1999;42:855-60.

25. Cho JH, Jeong YS, Lee YJ, et al. The Korean version of the Sniffin' stick (KVSS) test and its validity in comparison with the cross-cultura smell identification test (CC-SIT). Auris Nasus Larynx 2009;36:280-6.

26. Kong IG, Kim SY, Kim MS, et al. Olfactory dysfunction is associated with the intake of macronutrients in Korean adults. PLoS One 2016;11:e0164495

27. Brämerson A, Johansson L, Ek L, et al. Prevalence of olfactory dysfunction: the skövde population-based study. Laryngoscope 2004;114:733-7.

28. Watanabe S, Fukuchi Y. [Occupational impairment of the olfactory sense of chromate producing workers (author's transl)]. Sangyo Igaku 1981;23:606-11.

29. Rose CS, Heywood PG, Costanzo RM. Olfactory impairment after chronic occupational cadmium exposure. J Occup Med 1992;34:600-5.

30. Mascagni P, Consonni D, Bregante G, et al. Olfactory function in workers exposed to moderate airborne cadmium levels. Neurotoxicology 2003;24(4-5):717-24.

31. Rydzewski B, Sułkowski W, Miarzyńska M. Olfactory disorders induced by cadmium exposure: a clinical study. Int J Occup Med Environ Health 1998;11:235-45.

32. Antunes MB, Bowler R, Doty RL. San Francisco/Oakland Bay Bridge Welder study: olfactory function. Neurology 2007;69:1278-84.

33. Safe Work Australia. Controling risks associated with electroplating. 2012.

34. Cavallo DM, Cattaneo A. [Environmental and biological monitoring in the plating industry]. G Ital Med Lav Ergon 2012;34:247-50.

35. Azari MR, Hosseini V, Jafari MJ, et al. Evaluation of occupational exposure of shoe makers to benzene and toluene compounds in shoe manufacturing workshops in East tehran. Tanaffos 2012;11:43-9.

36. Occupational Safety and Health Branch Labour Department. Chemical safety in the workplace: guidance notes on chemical safety in printing industry. http://www.labour.gov.hk/eng/public/os/C/GN Printing.pdf (Accessed 29 Jan 2018).

37. US Department of Labor. Autobody repair and refenishing: Hazards and Solutions. https://www.osha.gov/SLTC/autobody/hazards.html (Accessed 29 Jan 2018).

38. ILO-CIS. International hazard datasheets on occupation: Mechanic Automobile. http://www.ilo.org/wcmsp5/groups/public/ed_protect/-protrav/-safework/documents/publication/wcms_ 193167.pdf (Accessed 6 Feb 2018). 